\title{
The outcome of prevention of mother-to-child transmission of HIV infection at King Abdulaziz University Hospital, Western Region of Saudi Arabia
}

\author{
A Descriptive Study
}

Elaf H. Ahmed, MBBs, Mayar A. Shafei, MBBs, Leena S. Alsubhi, MBBs, Noora A. Zarban, MBBs, Bashair A. Al-Zahrani, MBBs, Mohammed Shaikhomer, MD, MPH.

\begin{abstract}

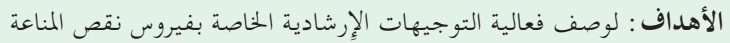

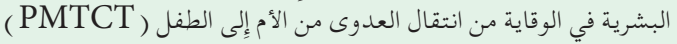

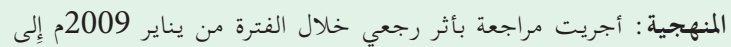

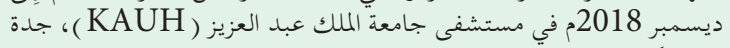

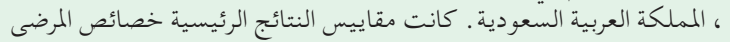

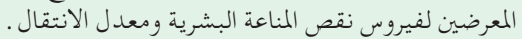

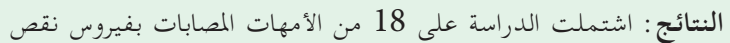

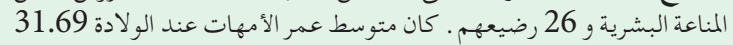

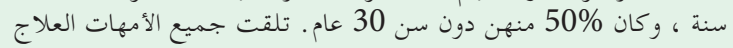

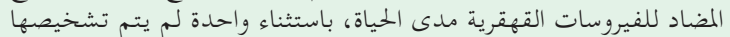

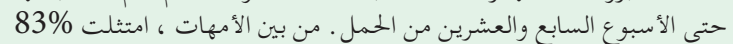

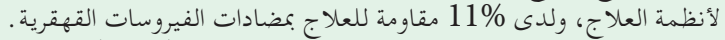

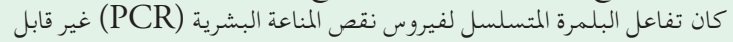

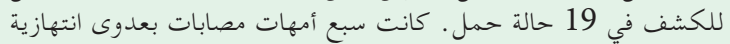

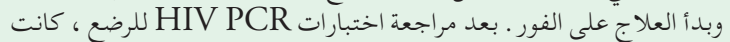
معدلات انتقال فيروس نقص الفور بلمد مراجعة اختبارات البشرية 0\% لكل من الولادة المهبلية

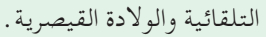

الخلاصة : تواجه العديد مني التحديات الجهود المبذولة لتقليل انتقال فيروس

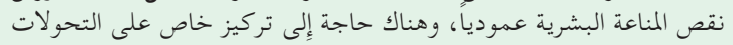

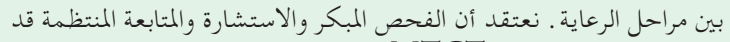

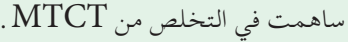

Objectives: To describe the effectiveness of HIV guidelines in prevention of mother-to-child transmission (PMTCT).

Methods: A retrospective review from January 2009 to December 2018 at the King Abdulaziz University Hospital (KAUH), Jeddah, Kingdom of Saudi Arabia. The main outcome measures were characteristics of HIV-exposed patients and transmission rate.

Results: A total of $18 \mathrm{HIV}$-positive mothers and their 26 infants were included. The mean age of mothers at delivery was 31.69 years, and $50 \%$ were under 30 years old. All mothers received lifelong ART, except one who was not diagnosed until the 27 th week of gestation. Among the mothers, $83 \%$ complied with treatment regimens, and $11 \%$ had ART resistance. Human immunodeficiency virus polymerase chain reaction (PCR) was undetectable in 19 pregnancies. Seven mothers had opportunistic infections and treatment was immediately initiated. After reviewing the infants' HIV PCR tests, the transmission rates of HIV were $0 \%$ for both spontaneous vaginal delivery and cesarean section.

Conclusion: Many challenges face the efforts to decrease vertical HIV transmission, and a particular focus on the transitions between stages of care is needed. We believe that early screening, counseling, and regular follow-up have contributed to MTCT elimination.

Keywords: human immunodeficiency virus; transmission, prevention

Saudi Med J 2021; Vol. 42 (9): 1009-1016 doi: 10.15537/smj.2021.42.9.20200789

From the King Abdulaziz University, Jeddah, Kingdom of Saudi Arabia.

Received 20th June 2021. Accepted 10th August 2021.

Address correspondence and reprint request to: Dr. Mohammed Shaikhomer, Department of Medicine, Faculty of Medicine, King Abdulaziz University, Jeddah, Kingdom of Saudi Arabia. E-mail: mohammed.shaikhomer@gmail.com

ORCID ID: http://orcid.org/0000-0002-5511-7412

Disclosure. Authors have no conflict of interests, and the work was not supported or funded by any drug company. 
T here has been a noticeable increase in the extent of the human immunodeficiency virus (HIV), impacting individuals, population health, and economic growth. ${ }^{1}$ In Saudi Arabia, 10,217 HIV cases were recorded between 2000 and 2009; this number has been increasing each year. ${ }^{2}$ The high incidence of HIV brings to attention the need to establish multiple strategies that minimize the prevalence rate. The Saudi Ministry of Health $(\mathrm{MOH})$ has reported that total elimination of HIV would be achieved by 2030, through the "90-90-90: Strategy for the Eradication of HIV."3 This is applied by early HIV screening so that medical treatment can be provided before symptoms develop, which will reduce patient mortality and prevent HIV spread. ${ }^{4}$ Previously, screening was voluntary and only for pregnant women at high risk for HIV infection. ${ }^{4,5}$ Nowadays, screening is mandatory during antenatal visits, to prevent motherto-child transmission (MTCT) of HIV. Mother-tochild transmission can occur in utero, intrapartum, and through breastfeeding, the cumulative rate of MTCT of HIV without medical care was 35-40\%., Furthermore, transmission could be minimized to less than $1 \%$ through adherence to antiretroviral therapy (ART) during gestation. ${ }^{7}$ Furthermore, the optimal mode of delivery may reduce the rate to less than $2 \% .{ }^{8}$ Polymerase chain reaction (PCR) tests are reliable in detecting HIV during gestation and in the neonatal period. ${ }^{9}$

This study aimed to review the approaches followed at the King Abdulaziz University Hospital (KAUH), Jeddah, Saudi Arabia, with HIV-positive mothers and infants outcomes from 2009 to 2018.

Methods. This is a retrospective descriptive study targeting all HIV-positive mothers and their delivered infants from January 2009 to December 2018 at KAUH. The ethical committee of KAUH has approved this study. We excluded 3 infants: 2 twins considering the high risk of infection in the firstborn twin, and one infant whose file could not be accessed. Our sample size included $18 \mathrm{HIV}$-positive mothers aged 24 to 50 years old and their 26 infants. The mothers were already known cases of HIV except for one who was diagnosed, in the 27th week of pregnancy during antenatal visits, based on enzyme-linked immunosorbent assay (ELISA) and Western blot tests. Descriptive data were created for all variables, based on KAUH's strategies followed by the AIDS Clinical Trials Group Protocol 076 to reduce the risk of MTCT of HIV ${ }^{10}$ consisting of the mother's current treatment, compliance, and resistance to ART, and immunologic and virologic statuses.
Other variables were near-term CD4 T-lymphocyte counts (categorized as $<200$ cells, 200-399, and $\geq 400$ cells $/ \mathrm{mm}^{3}$ ), intrapartum prophylaxis, and mode of delivery. Antenatal visits and coinfections diagnosed in pregnancy were recorded as well as gestational age measured by ultrasound (US). Newborn data included HIV PCR tests and HIV antibody measurements calculated at birth and 2 to 4, 6, 12, and 18 months. It also comprised infant gender, birth weight, Apgar score, postpartum prophylaxis, and breast feeding status. All data were obtained from the medical records, and infants who lost to follow-up in the pediatric clinic were reported. Simple descriptive statistics including percentages, means, and standard deviations were calculated using Microsoft Excel.

Results. We reviewed the medical records of 18 mothers and their 26 infants delivered at KAUH between 2009 and 2018. The mean age of mothers at delivery was 31.69 years, and $50 \%$ were under 30 years old. All of them were prescribed lifelong ART before pregnancy, except for one mother who started ART at 27 weeks of pregnancy. During 15 of the pregnancies $(65.2 \%)$, the mothers were receiving nucleoside reverse-transcriptase inhibitor (NRTI) therapy plus a protease inhibitor (PI); in 4 pregnancies $(17.4 \%)$, the mothers were receiving NRTI/non-nucleoside reverse-transcriptase inhibitor (NNRTI) therapy; in 2 pregnancies $(8.7 \%)$, they were on NRTI/PI/integrase inhibitor (IH); in 1 pregnancy (4.3\%), the mother was on NRTI/IH; and in 1 (4.3\%), the mother was on NRTI/NNRTI/PI.

Table 1 details the types of ART used by the HIVpositive mothers for each pregnancy concerning their CD4 cell counts. Fifteen mothers were compliant with their treatment regimens while 3 were not compliant, because of either depression or expiration of ID (iqama), and one mother had an unknown reason in her 3 pregnancies. Antiretroviral therapy resistance was noticed in 2 cases; one was a non-compliant mother with depression for one year, who developed resistance to the NRTI emtricitabine and was then assigned to a PIs/ NRTI combination (boosted lopinavir, Truvada, and raltegravir). The other patient acquired resistance to the combination NRTI/ NNRTI/ PI and was treated with boosted lopinavir, lamivudine, and efavirenz, which was later switched to the NRTI/PIs (Truvada, boosted darunavir and raltegravir). Twenty of the 26 pregnancies (76.9\%) ended with vaginal delivery. Eighteen of the patients who delivered vaginally had undetectable viral loads; however, 2 had CSs planned but delivered by emergency SVD instead. Their viral loads reached 49,421 and 4,245 copies/mL. Six pregnancies were 
delivered by CS: 4 were associated with a viral load of more than 1000 copies/ $\mathrm{mL}$, and the remaining $2 \mathrm{had}$ undetectable viral loads (one was accompanied with AIDS and a history of pulmonary tuberculosis, while the other had the obstetric indication severe preeclampsia).
Table 2 summarizes the deliveries of the HIVpositive mothers in relation to total deliveries each year, compliance with ART in the antenatal period, and the effect of viral load on the mode of delivery. All mothers received zidovudine (AZT) prophylaxis during labor

Table 1 - Types of ART used in the treatment of HIV-positive mothers in relation to their CD4 cell counts.

\begin{tabular}{lccccccc}
\hline ART & PI/NRTI & NNRTI/NRTI & $\begin{array}{c}\text { PI/NRTI, } \\
\text { NNRTI }\end{array}$ & $\begin{array}{c}\text { NRTI and } \\
\text { IH }\end{array}$ & PI, NRTI, IH & Missing & Total \\
\hline Pregnancies & $15(15.4)$ & $4(15.4)$ & $1(3.8)$ & $1(3.8)$ & $2(7.7)$ & $3(11.5)$ & $26(100)$ \\
CD4 $>400$ & 9 & 4 & 1 & 1 & - & - & $17(65.4)$ \\
CD4 200-400 & 3 & - & - & - & - & - & $3(11.5)$ \\
CD4 $<200$ & 1 & - & - & - & 2 & - \\
\hline
\end{tabular}

Values are expressed as number and percentage (\%). ART: antiretroviral therapy, IH: integrase inhibitors, NNRTI: non-nucleoside reverse transcriptase inhibitor, NRTI: nucleoside reverse transcriptase inhibitor, PI: protease inhibitors

Table 2 - Number of deliveries of the HIV-positive mothers related to total deliveries each year, their compliance to ART antenatally, and the effect of the viral load on mode of delivery $(\mathrm{N}=26)$.

\begin{tabular}{|c|c|c|c|c|c|}
\hline Year & $\begin{array}{c}\text { Total number of } \\
\text { mothers who gave } \\
\text { birth }\end{array}$ & $\begin{array}{l}\text { HIV-mothers who } \\
\text { gave birth }\end{array}$ & Compliance with ART & Viral load (copies/mL) & Mode of delivery \\
\hline 2018 & 5698 & 1 mother & Compliant & 952,038 & Emergency CS \\
\hline \multirow[t]{2}{*}{2017} & 4321 & 2 mothers & Compliant & Undetectable & Emergency SVD \\
\hline & & & Compliant & Undetectable & Emergency SVD \\
\hline \multirow[t]{4}{*}{2016} & 3997 & 4 mothers & Noncompliant & 52,997 & Elective CS \\
\hline & & & Noncompliant & 9,292 & Elective CS \\
\hline & & & Compliant & Undetectable & Emergency SVD \\
\hline & & & Compliant & Undetectable & Emergency SVD \\
\hline \multirow[t]{5}{*}{2015} & 3553 & 5 mothers & Noncompliant & 3,822 & Elective CS \\
\hline & & & Compliant & Undetectable & Elective CS \\
\hline & & & Compliant & Undetectable & Elective SVD \\
\hline & & & Compliant & Undetectable & Emergency SVD \\
\hline & & & Compliant & Undetectable & Emergency SVD \\
\hline \multirow[t]{2}{*}{2014} & 3283 & 2 mothers & Compliant & Undetectable & Elective CS \\
\hline & & & Compliant & Undetectable & Elective SVD \\
\hline \multirow[t]{6}{*}{2013} & 4373 & 6 mothers & $\begin{array}{c}\text { Compliant (newly } \\
\text { diagnosed at } 27 \text { weeks) }\end{array}$ & 49,421 & Emergency SVD \\
\hline & & & Compliant & 41 & Elective SVD \\
\hline & & & Compliant & 28 & Emergency SVD \\
\hline & & & Compliant & Undetectable & Emergency SVD \\
\hline & & & Compliant & Undetectable & Emergency SVD \\
\hline & & & Noncompliant & Undetectable & Elective SVD \\
\hline \multirow[t]{3}{*}{2012} & 4599 & 3 mothers & Compliant & Undetectable & Emergency SVD \\
\hline & & & Compliant & Undetectable & Emergency SVD \\
\hline & & & Compliant & Undetectable & Emergency SVD \\
\hline 2011 & 4766 & 1 mother & Noncompliant & 4,245 & Emergency SVD \\
\hline 2010 & 4238 & 1 mother & Compliant & 213 & Emergency SVD \\
\hline 2009 & 4243 & 1 mother & Compliant & Undetectable & Emergency SVD \\
\hline
\end{tabular}




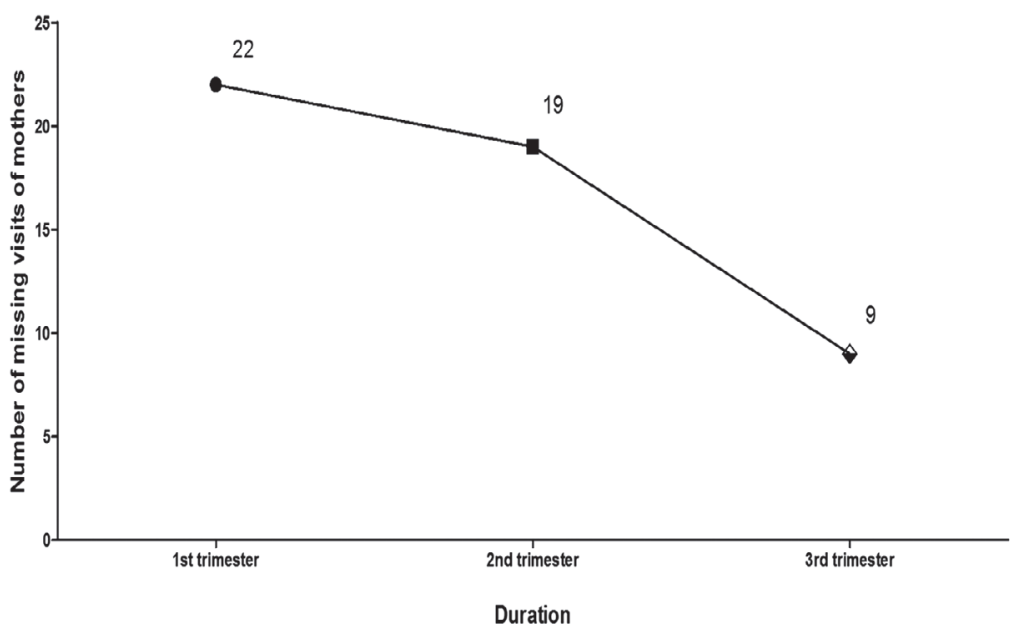

Figure 1 - Missed antenatal visits of HIV-positive mothers for each pregnancy (N=26).

as part of hospital protocol. Opportunistic infections were found in 7 mothers (during 11 pregnancies), with one of the following infections for each: disseminated cytomegalovirus, Pneumocystis carinii pneumonia, intra-abdominal tuberculosis, Human papillomavirus type 6, Candida esophagitis, cryptococcosis of the central nervous system, and pulmonary tuberculosis. All mothers started treatment at the time of diagnosis. There were 18 recorded antenatal visits for 26 pregnancies. The highest number of visits were registered in the third trimester; as they became closer to their due dates.

Figure 1 shows the number of missed antenatal visits. Each of the 26 newborn babies was carefully checked after birth by 1- and 5- minute Apgar scores: 1-minute scores were recorded for 25 of the newborns, and the score was missing for one newborn. The lowest scores were found in 2 newborns, who scored 2 and 6 out of 10 ( $8 \%$ of the cases), indicating that the infants required ventilation assistance and immediate resuscitation. However, in $96.2 \%$ of the cases, the 5-minute Apgar score was reassuring. The infant mortality rate was $0.04(3.8 \%)$, which was a case with severe intrauterine growth restriction (IUGR).

Table 3 shows an overview of newborn characteristics. Human immunodeficiency virus PCR results of samples that were collected after birth were undetectable for all newborns. None of the newborns proved to have HIV infection since there were no 2 consecutive positive HIV PCR assays confirmed. Furthermore, the HIV-antibody test was positive in 4 cases. Laboratory test results are summarized in Table 4.
Table 3 - Characteristics of HIV-positive mothers' newborns (N=26).

\begin{tabular}{|c|c|c|}
\hline Characteristics & $\mathbf{n}$ & $(\%)$ \\
\hline \multicolumn{3}{|l|}{ Gender $(n=26)$} \\
\hline Boys & 17 & $(65.4)$ \\
\hline Girls & 9 & $(34.6)$ \\
\hline \multicolumn{3}{|l|}{ Birth Weight $(n=26)$} \\
\hline Underweight $(<2.5 \mathrm{~kg})$ & 9 & $(34.6)$ \\
\hline Normal weight $(2.5-4.5 \mathrm{~kg})$ & 17 & $(65.4)$ \\
\hline Apgar score at 1 min (out of 10), $(n=25)$ & $8.40 \pm 1.53$ & $3(2.0-9.0)$ \\
\hline Resourcing score $(7,8$ and 9$)$ & 23 & $(92.0)$ \\
\hline Fair score $(6,5$ and 4$)$ & 1 & $(3.8)$ \\
\hline Low Apgar score (below 3) & 1 & $(3.8)$ \\
\hline Apgar score at 5 min (out of 10), $(n=25)$ & $9.42 \pm 2.00$ & $(0.0-10.0)$ \\
\hline Resourcing score $(7,8$ and 9$)$ & & $(96.1)$ \\
\hline Fair score $(6,5$ and 4$)$ & - & - \\
\hline Low Apgar score (below 3) & 1 & $(3.8)$ \\
\hline Prophylaxis $(\mathrm{n}=25)$ & 25 & $(96.2)$ \\
\hline Infant mortality $(\mathrm{n}=26)$ & $\begin{array}{l}1 \text { (due to } \\
\text { IUGR) }\end{array}$ & $(3.8)$ \\
\hline
\end{tabular}

Data are expressed as number (\%) or mean $+/$ - standard deviation (minimum-maximum). IUGR: intrauterine growth restriction.

Figure 2 shows the number of HIV-exposed infants who were lost to follow-up for unclear reasons.

Discussion. The most significant policies legislated to restrict HIV transmission in Saudi Arabia include lifelong ART for HIV-positive women and AZT prophylaxis during labor. For the newborn, exclusive formula feeding plus AZT prophylaxis starting 
from birth to 6 weeks of life will decrease the risk of transmission to less than $2 \% .^{11,12}$ In some settings, these strategies may not be sufficient to prevent MTCT of HIV and HIV antigens could be detected. This study was designed to describe the PMTCT of HIV between 2009 and 2018 at KAUH and to discuss how HIV screening tests could change the epidemiology of HIV in Saudi Arabia. Maternal HIV viral load is considered the most critical factor in determining

Table 4 - Laboratory test results for HIV-exposed children, $(\mathrm{N}=25)^{*}$

\begin{tabular}{lrl}
\hline Laboratory test & n & $(\%)$ \\
\hline At birth $(\boldsymbol{n}=26)$ & & \\
PCR undetectable & 25 & $(96.2)$ \\
ELASIA positive & 4 & $(15.4)$ \\
Western blot positive & 3 & $(11.5)$ \\
At 6 weeks & & \\
PCR undetectable & 19 & $(73.1)$ \\
ELASIA positive & 3 & $(11.5)$ \\
Western blot positive & 1 & $(3.8)$ \\
At 6 months & & \\
PCR undetectable & 8 & $(30.8)$ \\
ELASIA positive & 1 & $(3.8)$ \\
At 12 months & & \\
PCR undetectable & 3 & $(11.5)$ \\
ELASIA positive & 1 & $(3.80$ \\
At 18 months & & \\
PCR undetectable & 3 & $(11.5)$ \\
ELASIA positive & 1 & $(3.8)$ \\
\hline *Excluding one infant who died immediately after birth. \\
Abbreviations: PCR, polymerase chain reaction; ELASIA, enzyme- \\
$\quad$ linked immunosorbent assay.
\end{tabular}

full viral suppression after the initiation of ART by the time of delivery. ${ }^{13}$ A study has reported that HIV transmission rates were $20 \%$ for untreated women and $1.2 \%$ for women receiving ART. ${ }^{14}$ In this study, ZDV was used during the intrapartum period, following the AIDS Clinical Trials Group 076 Protocol, ${ }^{10}$ to reduce transmission risk. According to this study, the majority of the mothers had undetectable viral loads by the time of delivery $(64.4 \%)$, and eventually, the transmission rate was zero. These low rates were comparable to other studies. ${ }^{15,16}$ Moreover, we observed no transmission among 9 cases with detectable viral loads, due to either failure of diagnosing HIV at the right time or inability to control HIV replication because of nonadherence to regimens. ${ }^{17,18}$

The data in the study described the loss to follow-up (LTFU) in infants after delivery, based on clinic schedules. The median ages at first and last infant follow-up visits were 3 weeks and 18 months, respectively. The reason for their LTFU could be that when the infant's first HIV PCR result is negative, the mother dismisses further follow-up. ${ }^{19}$ The major challenge facing today's PMTCT care program is keeping the patients under medical care, typically up to 24 months of age. A meta-analysis of HIV-exposed infants showed that their LTFU within 3 months of birth was $33.9 \% .{ }^{20}$ These analyses determine the magnitude of LTFU, which is critical to the global PMTCT response. Exploring the reasons for LTFU may be used to inform further policy development and resource allocation for PMTCT programs to achieve the elimination of pediatric HIV infection in the Kingdom of Saudi Arabia.

Our findings also emphasize the ongoing need for preconception care of HIV-positive women, because they present later in pregnancy than what is recommended

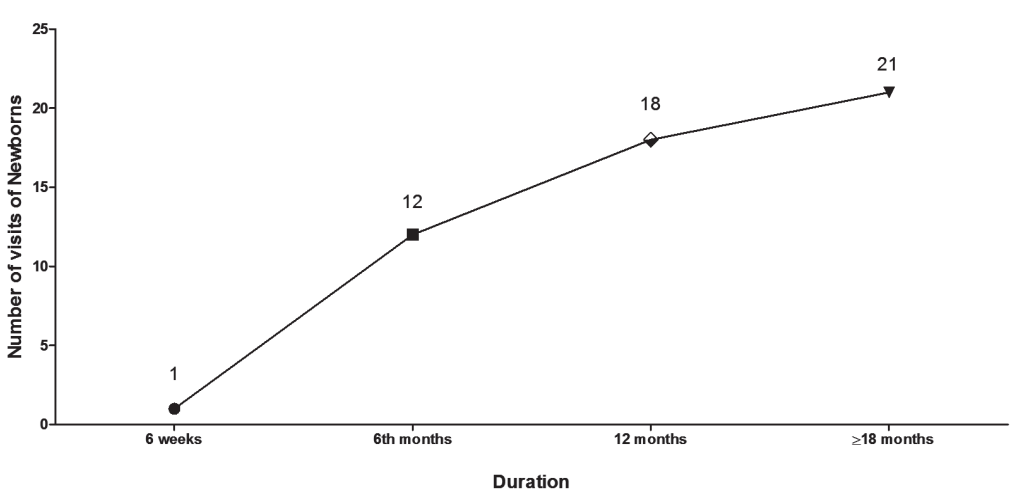

Figure 2 - Number of HIV-exposed infants lost to follow-up (LTFU) ( $\left.\mathrm{n}=25^{*}\right) .{ }^{*}$ Excluding one infant who died immediately after birth. 
by current guidelines. ${ }^{21}$ This study strongly emphasized the implementation of research to evaluate ways to improve the integration of services, ${ }^{22}$ particularly transitions from antenatal to delivery and pediatric care. A variety of research-based studies suggest strategies to improve follow-up care for HIV-exposed infants, such as an integration of services, ${ }^{22}$ male husband, ${ }^{23}$ active patient tracking, ${ }^{24}$ nutritional supplements, ${ }^{25}$ use of mobile technology for reminders, ${ }^{22}$ and accompaniment between clinics. ${ }^{26}$

Although the interpretation of infant outcomes in the study was limited due to LTFU even with available DNA PCR results, outcomes were excellent, especially among infants whose mothers were compliant within the PMTCT care program. A previous study noted that $35 \%$ of HIV-positive infants not receiving ART were expected to die during the first year of life and $52 \%$ by 2 years of age. ${ }^{27}$ These findings support that follow-up and early initiation of ART will suppress the viral load, slow disease progression, and reduce mortality rates. ${ }^{27}$ Additionally, the study did not adequately identify women at risk. However, since the overall rate of transmission was statistically equivalent to zero, it suggests that large-scale prevention applications have the potential to achieve superior results.

The principles of $\mathrm{MOH}$ recommendations for HIV screening of pregnant women have remained unchanged for a long time in Saudi Arabia. Human immunodeficiency virus screening was voluntary and offered only for high-risk women during antenatal visits, ${ }^{28}$ and the $\mathrm{MOH}$ has enforced the HIV screening test for all pregnant women as a routine part of prenatal care in 2019. There remains a particular challenge facing the screening program. For instance, screening services are unacceptable among Saudi individuals, partially due to lack of awareness about HIV and not expecting that it exists in Arab, Muslim cultures. Instead, most men and women do not realize that they are potentially at risk. Often, these limitations have served to not adhere with the guidelines, ${ }^{29}$ even with the established laws by the Bureau of Experts at the Council of Ministers; a Saudi citizen who is infected with HIV is entitled to free medical care and has the protection of his or her privacy. ${ }^{30}$ Even though, we acknowledge that effective programs are complicated by social barriers, stigmatization, and discrimination associated with the disease, all of which may prevent individuals from seeking voluntary HIV testing and counseling. ${ }^{31}$

Finally, the screening test should be modified to ensure that it is accessible across the country, such as to the $17.9 \%$ of the population living in rural areas. ${ }^{32}$ More awareness campaigns, educational seminars, and innovative healthcare policies for attracting Saudi pregnant women to undergo HIV screening tests are fundamentally needed.

Intrapartum care for HIV-positive mothers includes $2 \mathrm{mg} / \mathrm{kg} / \mathrm{hour}$ of AZT followed by $1 \mathrm{mg} / \mathrm{kg} / \mathrm{hour}$ administered intravenously as soon as signs of labor begin and until the infant is delivered. Within the first 8 to 12 hours after birth, the newborn infant should receive AZT syrup $2 \mathrm{mg} / \mathrm{kg} /$ dose every 6 hours for 6 weeks. If the mother's viral load is above 1000 copies $/ \mathrm{mL}, \mathrm{CS}$ is preferred to prevent MTCT, and AZT must be administered 3 hours before the procedure and until the newborn is delivered. Otherwise, vaginal delivery is recommended. ${ }^{28}$ There is no need to isolate the mother or her baby; however, breast feeding is contraindicated. Postpartum care for HIV-exposed newborns includes referring to an infectious disease pediatrician to determine the baby's status. The diagnosis of HIV in exposed infants depends on serial blood tests: HIV antibody test (ELISA), and HIV viral load measurements (PCR test). ${ }^{33}$

Study limitations. While the present study provides insights into the prevention of MTCT of HIV, it has been affected by some limitations. First is the small number of enrolled subjects which may affect the generalization of our findings among all Saudi regions. The second limitation is being conducted from a single center which may carry some sort of selection bias and affects the credibility of our results. Nonetheless, we believe that this report is a preliminary groundwork for future research in Saudi Arabia aiming to curb HIV transmission to newborns.

In conclusion, ensuring HIV screening for all pregnant women is crucial to detect the disease and prevent transmission to newborns. Various studies have assessed the efficacy of screening tests, counseling, ART, elective CS, breastfeeding avoidance, and early ART for newborns; and all have contributed to MTCT elimination. Therefore, it is important to establish HIV/acquired immunodeficiency syndrome (AIDS) awareness and educational efforts together with mandating HIV screening programs and linking to care which can lead to MTCT elimination in the community.

Acknowledgment. The authors gratefully thank Editage for their language editing services. 


\section{References}

1. Mondal MNI, Shitan M. Factors affecting the HIV/AIDS epidemic: an ecological analysis of global data. Afr Health Sci 2013; 13: 301-310.

2. Madani TA, Al-Mazrou YY, Al-Jeffri MH, Al Huzaim NS. Epidemiology of the human immunodeficiency virus in Saudi Arabia; 18-year surveillance results and prevention from an Islamic perspective. BMC Infect Dis 2004; 4: 25.

3. Sennaroglu L, Bajin MD. Management of stapes footplate fistula in inner ear malformations. International Journal of Pediatric Otorhinolaryngology 2021; 140: 110525.

4. Patel D, Johnson CH, Krueger A, Maciak B, Belcher L, Harris $\mathrm{N}$, DiNenno EA. Trends in HIV testing among US adults, aged 18-64 years, 2011-2017. AIDS Behav 2020; 24: 532-539.

5. Almilaibary AA. A mixed methods study of the factors associated with HIV testing uptake among young people in Saudi Arabia. Academic Journals 2018; 10: 96-102.

6. Vrazo AC, Sullivan D, Phelps BR. Eliminating mother-to-child transmission of HIV by 2030: 5 strategies to ensure continued progress. Glob Health Sci Pract 2018; 6: 249-256.

7. Barral MFM, de Oliveira GR, Lobato RC, Mendoza-Sassi RA, Martínez AMB, Gonçalves CV. Risk factors of HIV-1 vertical transmission (VT) and the influence of antiretroviral therapy (ART) in pregnancy outcome. Rev Inst Med Trop Sao Paulo 2014; 56: 133-138.

8. Arora N, Sadovsky Y, Dermody TS, Coyne CB. Microbial vertical transmission during human pregnancy. Cell Host Microbe 2017; 21: 561-567.

9. Chen X, Laurent S, Onur OA, Kleineberg NN, Fink GR, Schweitzer F, et al. A systematic review of neurological symptoms and complications of COVID-19. J Neurol 2021; 268: 392-402.

10. Connor EM, Sperling RS, Gelber R, Kiselev P, Scott G, O'Sullivan MJ, et al. Reduction of maternal-infant transmission of human immunodeficiency virus type 1 with zidovudine treatment. Pediatric AIDS Clinical Trials Group Protocol 076 Study Group. N Engl J Med 1994; 331: 1173-1180.

11. Townsend CL, Cortina-Borja M, Peckham CS, de Ruiter A, Lyall H, Tookey PA. Low rates of mother-to-child transmission of HIV following effective pregnancy interventions in the United Kingdom and Ireland, 2000-2006. AIDS 2008; 22: 973-981.

12. Myer L, Phillips TK, McIntyre JA, Hsiao NY, Petro G, Zerbe A, Ramjith J, Bekker LG, Abrams EJ. HIV viraemia and motherto-child transmission risk after antiretroviral therapy initiation in pregnancy in Cape Town, South Africa. HIV Med 2017; 18: 80-88.

13. Read PJ, Mandalia S, Khan P, Harrisson U, Naftalin C, Gilleece $\mathrm{Y}$, et al. When should HAART be initiated in pregnancy to achieve an undetectable HIV viral load by delivery? AIDS 2012; 26: 1095-1103.

14. Cooper ER, Charurat M, Mofenson L, Hanson IC, Pitt J, Diaz $\mathrm{C}$, et al. Combination antiretroviral strategies for the treatment of pregnant HIV-1-infected women and prevention of perinatal HIV-1 transmission. J Acquir Immune Defic Syndr 2002; 29: 484-494.

15. Achievements in public health. Reduction in perinatal transmission of HIV infection--United States, 1985-2005. MMWR Morb Mortal Wkly Rep 2006; 55: 592-597.
16. Boer K, Nellen JF, Patel D, Timmermans S, Tempelman C, Wibaut M, et al. The AmRo study: pregnancy outcome in HIV1 -infected women under effective highly active antiretroviral therapy and a policy of vaginal delivery. BJOG 2007; 114 : 148-155.

17. Scott GB, Brogly SB, Muenz D, Stek AM, Read JS, International Maternal Pediatric Adolescent AIDS Clinical Trials Group, P1025 Study Team. Missed opportunities for prevention of mother-to-child transmission of human immunodeficiency virus. Obstet Gynecol 2017; 129: 621-628.

18. Siemieniuk RA, Jadavji T, Gill MJ. Limitations of opt-out HIV screening and mother-child HIV transmission. Am J Public Health 2010; 100: 388-389; author reply 389.

19. Shargie MB, Eek F, Abaychew A. Prophylactic treatment uptake and compliance with recommended follow up among HIV exposed infants: a retrospective study in Addis Ababa, Ethiopia. BMC Res Notes 2011; 4: 563.

20. Sibanda EL, Weller IV, Hakim JG, Cowan FM. The magnitude of loss to follow-up of HIV-exposed infants along the prevention of mother-to-child HIV transmission continuum of care: a systematic review and meta-analysis. AIDS 2013; 27: 2787-2797.

21. American College of Obstetricians and Gynecologists. Labor and delivery management of women with human immunodeficiency virus infection. [Updte 2018; Access 2020 Sept 4]. Available from: https://www.acog.org/clinical/ clinical-guidance/committee-opinion/articles/2018/09/ labor-and-delivery-management-of-women-with-humanimmunodeficiency-virus-infection

22. Tudor Car L, van-Velthoven MH, Brusamento S, Elmoniry $\mathrm{H}$, Car J, Majeed A, et al. Integrating prevention of motherto-child HIV transmission (PMTCT) programmes with other health services for preventing HIV infection and improving HIV outcomes in developing countries. PLoS One 2012; 7 : e35268.

23. Farquhar C, Kiarie JN, Richardson BA, Kabura MN, John FN, Nduati RW, et al. Antenatal couple counseling increases uptake of interventions to prevent HIV-1 transmission. Journal of acquired immune deficiency syndromes (1999). J Acquir Immune Defic Syndr 2004; 37: 1620-1626.

24. Thomson KA, Cheti EO, Reid T. Implementation and outcomes of an active defaulter tracing system for HIV, prevention of mother to child transmission of HIV (PMTCT), and TB patients in Kibera, Nairobi, Kenya. Trans R Soc Trop Med Hyg 2011; 105: 320-326.

25. Kundu CK, Samanta M, Sarkar M, Bhattacharyya S, Chatterjee S. Food supplementation as an incentive to improve preantiretroviral therapy clinic adherence in HIV-positive children-experience from eastern India. J Trop Pediatr 2012; 58: 31-37.

26. Jani IV, Meggi B, Loquiha O, Tobaiwa O, Mudenyanga C, Zitha A, Mutsaka D, Mabunda N, Vubil A, Bollinger T, Vojnov L. Effect of point-of-care early infant diagnosis on antiretroviral therapy initiation and retention of patients. AIDS 2018; 32: 1453-1463.

27. Kiyaga C, Narayan V, McConnell I, Elyanu P, Kisaakye LN, Kekitiinwa A, et al. Retention outcomes and drivers of loss among HIV-exposed and infected infants in Uganda: a retrospective cohort study. BMC Infect Dis 2018; 18: 416.

28. Edathodu J, Halim MM, Dahham MB, Alrajhi AA. Motherto-child transmission of HIV: experience at a referral hospital in Saudi Arabia. Ann Saudi Med 2010; 30: 15-17. 
29. Fageeh WM. Should We Screen for HIV in Saudi Arabia? . JKAU: Med Sci 2010; 17: 45-54.

30. Bureau of Experts at the Council of Ministers. Attached to the system for the prevention of acquired immune deficiency syndrome (AIDS) and the rights and duties of sufferers. [Update 2018, Access 2020 Sept 4]. Available from: https:// laws.boe.gov.sa/BoeLaws/Laws/Viewer/bd60c847-24504d5a-a215-a9ed0119f68b?lawId=9d240ae2-a709-48ee-ac82a9ed0119f62d.

31. Mazroa MAAI, Kabbash IA, Felemban SM, Stephens GM, Al-Hakeem RF, Zumla AI, et al. HIV case notification rates in the Kingdom of Saudi Arabia over the past decade (20002009). PLoS One 2012; 7: e45919.
32. UN Habitat. Saudi Arabia - Urban Issues [Update 2021; Accessed 2020 Sept 4]. Available from: https://unhabitat.org/ saudi-arabia-urban-issues.

33. Association of Public Health Laboratories. Limitations for the use of HIV-1 western blot in plasma/serum. [cited 2015]. Available from: https://www.aphl.org/aboutAPHL/publications/ Documents/ID_HIV-1-1-WesternBlotBrief_62015.pdf

34. Styer LM, Sullivan TJ, Parker MM. Evaluation of an alternative supplemental testing strategy for HIV diagnosis by retrospective analysis of clinical HIV testing data. J Clin Virol 2011; 52 Suppl 1: S35-S40.

35. Masciotra S, McDougal JS, Feldman J, Sprinkle P, Wesolowski L, Owen SM. Evaluation of an alternative HIV diagnostic algorithm using specimens from seroconversion panels and persons with established HIV infections. J Clin Virol 2011; 52 Suppl 1: S17-S22. 